\title{
Original article \\ Effect of biopolymers containing natamycin against Aspergillus niger and Penicillium roquefortii on fresh kashar cheese
}

\author{
Hasan Ture, ${ }^{1}$ Erdal Eroglu, ${ }^{1}$ Banu Ozen ${ }^{2} *$ \& Ferda Soyer $^{3}$ \\ 1 Biotechnology and Bioengineering Programme, Izmir Institute of Technology, Urla-Izmir, Turkey \\ 2 Department of Food Engineering, Izmir Institute of Technology, Urla-Izmir, Turkey \\ 3 Department of Molecular Biology and Genetics, Izmir Institute of Technology, Urla-Izmir, Turkey
}

(Received 27 April 2010; Accepted in revised form 22 September 2010)

Summary Fungal spoilage during refrigerated storage is one of the main safety and quality-related problems for dairy products. The effect of wheat gluten (WG) and methyl cellulose (MC) biopolymers containing natamycin (NA) on the growth of Aspergillus niger and Penicillium roquefortii on the surface of fresh kashar cheese during storage at $10{ }^{\circ} \mathrm{C}$ for 30 days was investigated. Wrapping of $A$. niger-inoculated cheese with $\mathrm{MC}$ films containing 5-20 mg NA per $10 \mathrm{~g}$ resulted in approximately 2-log reductions in spore count. Two mg NA per $10 \mathrm{~g}$ included into WG films was sufficient to eliminate $A$. niger on the surface of cheese. However, MC and WG films containing NA did not cause any significant decrease in $P$. roquefortii count on the cheese surface. Therefore, especially use WG films in dairy applications could be an effective way of controlling A. niger growth on these products.

Keywords Antifungal agent, cheese, edible film, methylcellulose film, natamycin, wheat gluten film.

\section{Introduction}

One of the most important problems that affects the quality and shelf life of cheese is mould development on the surface because of the post-process contamination during handling and packaging of the product (de Oliveira et al., 2007). Fungal growth on dairy products not only causes economical losses but also results in health problems owing to mycotoxin production (Yildirim et al., 2006). Antimicrobial agents can be applied to food surfaces for controlling microbial growth by dipping, spraying, or brushing. However, these direct application techniques are laborious and have limited benefits (Min et al., 2005; Matche et al., 2006). A recent methodology proposed to maintain food safety and to extend the shelf life of the foods is the incorporation of natural antimicrobial agents into the bio-based packaging materials (Chinnan \& Cha, 2004).

Characterisation of biopolymers containing antimicrobial agents such as bacteriocins, plant extracts and enzymes has been performed by several researchers (Padgett et al., 2000; Scannell et al., 2000; Cagri et al., 2002; Sebti et al., 2005). Films prepared from wheat gluten (WG) are extensively studied protein-based

*Correspondent: E-mail:banuozen@iyte.edu.tr polymers (Gennadios et al., 1997; Micard et al., 2000; Guilbert et al., 2002; Lens et al., 2003; Domenek et al., 2004). WG forms films easily, is biodegradable and shows excellent oxygen and carbon dioxide resistance at low relative humidity (Roy et al., 1999; Micard et al., 2000). Cellulose, major structural component of plants, is one of the most abundant renewable resources, and its derivatives have excellent film-forming properties. Methyl cellulose (MC) films have flexible and transparent character. They also possess low oxygen and moisture vapour transmission rates when compared to other hydrophilic edible films (Debeaufort \& Voilley, 1997; Ruckenstein \& Park, 2001; Peressini et al., 2003).

Natamycin (NA) produced by fermentation using Streptomyces natalensis is an antifungal agent that was approved as a GRAS agent by Food and Drug Administration in the United States (Stark, 2003) and also designated as a natural preservative by the European Union (EEC no. 235). It is commonly used in many countries as a food additive to prevent the growth of moulds and yeasts on food products such as cheeses and sausages (Stark, 2003). Natamycin is suitable as a surface treatment agent because its low solubility causes it to remain mostly on the surface of the food product.

Extensive studies have been conducted to investigate the antimicrobial activity of films in in vitro systems 
(Cagri et al., 2001; Eswaranandam et al., 2004; Zivanovic et al., 2005; Sebastien et al., 2006). It was also shown that $\mathrm{MC}$ and $\mathrm{WG}$ films containing NA had antimycotic activity against Aspergillus niger and Penicillium roquefortii growth on potato dextrose agar (Ture et al., 2008). However, because of the application of different antimicrobial testing methods, growth medium and test microorganisms, conclusions on what type of these antimicrobial films are effective should be drawn after application of these films on food products (Quintavalla \& Vicini, 2002).

Several studies have reported that antimicrobial films containing NA possess potential ability to inhibit the microorganisms on food products. NA impregnated cellulose-based films showed inhibitory effect against $P$. roquefortii present on the surface of Gorgonzola cheese (de Oliveira et al., 2007). Combination of nisin and NA included into cellulose film formulation improved the shelf life of sliced Mozzarella cheese by 6 days compared to control (Santos et al., 2008). Chitosan coating containing $0.05 \mathrm{mg} \mathrm{mL}^{-1} \mathrm{NA}$ caused $1.1 \mathrm{log}$ CFU g ${ }^{-1}$ decrease in mould/yeast population on Saloio cheese after 27 days of storage (Fajardo et al., 2010).

The goal of the present study is to investigate the antifungal properties of $\mathrm{MC}$ and $\mathrm{WG}$ films containing NA against $A$. niger and $P$. roquefortii inoculated on the surface of fresh kashar cheese during 30 days of storage at refrigeration temperature.

\section{Materials and methods}

\section{Test microorganisms}

Aspergillus niger was isolated from onion skin in the Plant Protection Department of Mustafa Kemal University (Hatay, Turkey). P. roquefortii DBCI-1 was isolated from Danish blue cheese in the Food Engineering Department of Izmir Institute of Technology (Izmir, Turkey). Both fungi confirmed by microscopy and morphological analysis were grown on potato dextrose agar (PDA) (Merck, Darmstadt, Germany) at $30^{\circ} \mathrm{C}$. Cultures of 3-5-day-old A. niger and 5-7-day-old $P$. roquefortii were used throughout the study. Spore suspensions were prepared by using a modified method of Weng \& Chen (1997). Sterile 0.1\% peptone water was added to PDA slants. The PDA surface was gently scraped with an inoculation loop. The content was transferred to a sterile flask and shaken vigorously to liberate spores. Spore count was determined by enumerating the spores on a Thoma slide, and the spore suspension was adjusted to $10^{5}$ spores per $\mathrm{mL}$ with sterile $0.1 \%$ peptone water. Subculture of both moulds was carried out every 2 weeks to maintain viability, and the moulds were stored at $-80{ }^{\circ} \mathrm{C}$ in their media containing 20\% glycerol during the experiment. Dichloran Rose Bengal Chloramphenicol (DRBC) agar was purchased from Merck (Darmstadt, Germany) and was used as a selective media for the enumeration.

\section{Film preparation}

Pimalac ${ }^{\circledR}$ used as NA source was provided by Mayasan (Istanbul, Turkey). Wheat gluten films were prepared according to a method by Pochat-Bohatier et al. (2006) with some modifications. A solution was prepared by dissolving $15 \mathrm{~g}$ of WG (Sigma-Aldrich, Munich, Germany) in $31.5 \mathrm{~mL}$ absolute ethanol by mixing. Then, $0.03 \mathrm{~g}$ sodium sulphite, $3 \mathrm{~g}$ glycerol and $63 \mathrm{~mL}$ deionised water were added to the solution and homogenised with a magnetic stirrer for $10 \mathrm{~min}$. $\mathrm{pH}$ of film solution was adjusted to 4 with acetic acid, and solution was mixed and heated to $70{ }^{\circ} \mathrm{C}$ on a magnetic stirrer. Ten grams of film solution was spread onto polystyrene petri dishes (diameter $8.5 \mathrm{~cm}$ ) and allowed to dry at $30^{\circ} \mathrm{C}$.

A procedure by Turhan \& Şahbaz (2004) with some modifications was used for the preparation of MC films. After mixing $3 \mathrm{~g}$ MC (Sigma-Aldrich, Munich, Germany) with $50 \mathrm{~mL}$ deionised water, $50 \mathrm{~mL}$ ethanol was added and the solution was homogenised with a homogeniser (Heidolph-SilentCrusher M; Heidolph Instruments, Schwabach, Germany) at $25000 \mathrm{rpm}$. After the addition of $1 \mathrm{~mL}$ glycerol, the solution was heated to $80^{\circ} \mathrm{C}$. To cast the films, $10 \mathrm{~g}$ of film solution was spread onto polystyrene petri dishes and dried at $30{ }^{\circ} \mathrm{C}$.

Natamycin was incorporated into film solution at various concentrations as a powder. Antimycotic activities of MC and WG films containing 2, 5, 10 and $20 \mathrm{mg}$ NA per $10 \mathrm{~g}$ film solution were tested. To eliminate the adverse effect of the temperature, antimicrobial agent was added to film solution after cooling the solutions to a temperature between 50 and $55^{\circ} \mathrm{C}$.

\section{Sample preparation and inoculums}

Cheese samples were purchased from a local supermarket and transported immediately to the laboratory in an insulated box containing ice packs. One-centimetrethick cheese slices were cut into circular pieces $2 \mathrm{~cm}$ in diameter (approximately $20 \mathrm{~g}$ ) using a sterile beaker. Then, each surface was treated under UV light (254 nm) at a distance of $15 \mathrm{~cm}$ for $10 \mathrm{~min}$ to decrease the number of microbial flora on the surface of the samples. Sliced cheeses were dipped into $10^{5}$ spores $\mathrm{mL}^{-1}$ of either $A$. niger or $P$. roquefortii for $2 \mathrm{~min}$. Then, each surface was dried for $10 \mathrm{~min}$ under a laminar hood. Dried cheeses were placed between nearly $4.5-\mathrm{cm}$ circular diameter film pieces. The assembly was placed into sterile petri dishes, sealed with zipper-lock plastic bags and stored at $10{ }^{\circ} \mathrm{C}$ in a refrigerator for 30 days. Sample groups used during the experiment were as follows: (i) no treatment (T1) (ii) UV treated (T2) (iii) UV treated and inoculated with either $A$. niger or $P$. roquefortii (T3) 
(iv) UV treated + inoculated + control films (T4) (v) no treatment + control films (T5) (vi) UV treated + inoculated + antimicrobial films (T6-T10).

\section{Microbiological analysis}

Cheese sample groups were sampled after $2 \mathrm{~h}$ on day 0 and again after $10,20,30$ days of storage at $10{ }^{\circ} \mathrm{C}$ for microbiological analysis. Films were separated from cheese slices with sterile forceps, and samples were mixed with approximately $180 \mathrm{~mL}$ of $0.1 \%$ peptone water in a sterile stomacher bag and homogenised using a Stomacher (BagMixer, Interscience, Paris, France) at $230 \mathrm{rpm}$ for $2 \mathrm{~min}$. Appropriate dilutions with $0.1 \%$ peptone water were made, and $0.1 \mathrm{~mL}$ sample was spread on DRBC agar plates and incubated at $30^{\circ} \mathrm{C}$ for 2 days (Duan et al., 2007). All tests were carried out in duplicate.

\section{Statistical analysis}

Statistical analysis of data was performed using JMP statistical software program version 5 (SAS Institute Inc, Cary, NC, USA). A one-way analysis of variance followed by a Tukey's test $(P<0.05)$ was used to determine whether the differences between the treatments were significant.

\section{Results and Discussion}

The effects of MC and WG films containing NA on the growth of $A$. niger and $P$. roquefortii on fresh kashar cheese were investigated not only by examining visual mould decay but also by enumerating the fungal spores during 30-day storage at $10{ }^{\circ} \mathrm{C}$. Kashar cheese is one of the most commonly consumed dairy products in Turkey. It is classified as a semi-hard cheese, and it is regarded as similar to cheddar and mozzarella. In our previous study, the effective levels of NA were determined under in vitro conditions (Ture et al., 2008). According to this study, NA in both film types was inhibitory against $A$. niger and $P$. roquefortii at 2 and $1 \mathrm{mg}$ NA per $10 \mathrm{~g}$ film solution, respectively.

Effect of methyl cellulose and wheat gluten films containing natamycin on Aspergillus niger inoculated on cheese

Table 1 shows the effect of various concentrations of NA incorporated into MC films on the growth of A. niger. Several control sample groups were prepared to compare the efficiency of films containing NA: (T1) untreated, (T2) UV treated, (T3) A. niger inoculated, (T4) A. niger inoculated + control film and (T5) untreated + control film. After 20 days of storage, population of fungus on cheese sample groups that was untreated (T1), treated with UV (T2) and untreated and packaged with MC control film (T5) increased to $>10 \times$ level. As can be seen from the Table 1 that UV at $254 \mathrm{~nm}$ wavelength did not eliminate the predominant fungus present in control cheese over 30-day storage at refrigeration temperature. $\mathrm{T} 1, \mathrm{~T} 2$ and $\mathrm{T} 5$ were not inoculated with fungus but have the natural microflora of the cheese. This microflora contains different types of microorganisms, and they compete with each other for domination. Because of this competition, lag time of the natural flora might be longer than pure fungus inoculated on the surface of cheese; as a result, there is no significant growth for T1, T2 and T5 until day 20. However, once dominating fungus start growing, their number might increase suddenly after 20 days because of their easy adaptation to their natural environment (cheese).

Population of $A$. niger on inoculated cheese sample (T3 in Table 1) increased from 3.3 to $5.61 \mathrm{CFU} \mathrm{g}^{-1}$ during storage period. Approximately, 0.6-log reduction in fungal population of cheese samples wrapped with MC film which do not contain any NA (T4) was observed compared to unwrapped samples (T3) after 30 days of storage. This could be attributed to reduced $\mathrm{O}_{2}$ concentration in the package with respect to unpacked sample. There was no significant reduction in spore population on cheese packaged with MC film containing $2 \mathrm{mg}$ NA per $10 \mathrm{~g}$ film solution compared

Table 1 Effect of MC films containing NA on the population ( $\left.\log \mathrm{CFU} \mathrm{g}^{-1}\right)$ of Aspergillus niger on kashar cheese during storage

\begin{tabular}{|c|c|c|c|c|}
\hline Treatments & Day 0 & Day 10 & Day 20 & Day 30 \\
\hline No treatment (T1) & $<10^{a}$ & $<10^{\mathrm{a}}$ & $>10 x^{a}$ & \\
\hline UV-treated cheese (T2) & $<10^{\mathrm{a}}$ & $<10^{\mathrm{a}}$ & $>10 x^{a}$ & \\
\hline A. niger-inoculated cheese (T3) & $3.3 \pm 1.3^{b}$ & $3.26 \pm 0.56^{b}$ & $4.28 \pm 0.59^{b}$ & $5.61 \pm 0.49^{b}$ \\
\hline A. niger-inoculated $+\mathrm{MC}$ control film (T4) & $3.3 \pm 1.3^{b}$ & $3.1 \pm 0.51^{b c}$ & $3.19 \pm 0.57^{c}$ & $5 \pm 0.85^{c}$ \\
\hline No treatment cheese +MC control film (T5) & $<10^{\mathrm{a}}$ & $<10^{\mathrm{a}}$ & $>10 x^{a}$ & \\
\hline MC film containing 2 mg NA per $10 \mathrm{~g}$ film solution (T6) & $3.43 \pm 1.44^{b}$ & $2.81 \pm 0.24^{\mathrm{cd}}$ & $3.13 \pm 0.15^{\mathrm{c}}$ & $4.99 \pm 1.36^{\mathrm{c}}$ \\
\hline MC film containing 5 mg NA per $10 \mathrm{~g}$ film solution (T7) & $3.54 \pm 1.54^{\mathrm{b}}$ & $2.51 \pm 0.28^{d}$ & $3.29 \pm 0.55^{\mathrm{c}}$ & $3.57 \pm 0.69^{d}$ \\
\hline MC film containing $10 \mathrm{mg}$ NA per $10 \mathrm{~g}$ film solution (T8) & $3.35 \pm 1.35^{\mathrm{b}}$ & $2.6 \pm 0.21^{d}$ & $3.3 \pm 0.36^{c}$ & $3.56 \pm 1.29^{d}$ \\
\hline MC film containing $20 \mathrm{mg}$ NA per $10 \mathrm{~g}$ film solution (T9) & $3.34 \pm 1.35^{\mathrm{b}}$ & $2.65 \pm 0.11^{\mathrm{d}}$ & $3.21 \pm 0.15^{\mathrm{c}}$ & $3.63 \pm 0.85^{d}$ \\
\hline
\end{tabular}

${ }^{\mathrm{a}-\mathrm{d}}$ Same letters show that there is no statistical difference between treatments at $P>0.05$. 
Table 2 Effect of WG film containing NA on the population (log CFU g ${ }^{-1}$ ) of Aspergillus niger on kashar cheese during storage

\begin{tabular}{|c|c|c|c|c|}
\hline Treatments & Day 0 & Day 10 & Day 20 & Day 30 \\
\hline No treatment (T1) & $<10^{\mathrm{a}}$ & $<10^{\mathrm{a}}$ & $>10 x^{a}$ & \\
\hline UV-treated cheese (T2) & $<10^{\mathrm{a}}$ & $<10^{\mathrm{a}}$ & $>10 x^{a}$ & \\
\hline A. niger-inoculated cheese (Т3) & $4.06 \pm 0.97^{b}$ & $3.21 \pm 0.02^{\mathrm{bc}}$ & $6.89 \pm 1.68^{b}$ & $7.35 \pm 0.02^{\mathrm{b}}$ \\
\hline A. niger-inoculated + WG control film (T4) & $4.11 \pm 0.77^{\mathrm{b}}$ & $3.56 \pm 0.83^{b}$ & $3.17 \pm 1.04^{\mathrm{c}}$ & $3.24 \pm 0.02^{\mathrm{c}}$ \\
\hline No treatment cheese + WG control film (T5) & $<10^{\mathrm{a}}$ & $<10^{\mathrm{a}}$ & $>10 x^{a}$ & \\
\hline WG film containing $2 \mathrm{mg}$ NA per $10 \mathrm{~g}$ film solution (T6) & $3.99 \pm 1.35^{b}$ & $3.39 \pm 0.82^{\mathrm{bc}}$ & $2.7 \pm 0.63^{\mathrm{c}}$ & $<10^{\mathrm{d}}$ \\
\hline WG film containing $5 \mathrm{mg}$ NA per $10 \mathrm{~g}$ film solution (T7) & $4.07 \pm 0.99^{b}$ & $3.52 \pm 1.49^{b c}$ & $2.57 \pm 0.64^{\mathrm{c}}$ & $<10^{\mathrm{d}}$ \\
\hline WG film containing $10 \mathrm{mg}$ NA per $10 \mathrm{~g}$ film solution (T8) & $3.94 \pm 0.77^{b}$ & $3.04 \pm 0.82^{\mathrm{bc}}$ & $1.4 \pm 0.5^{\mathrm{d}}$ & $<10^{\mathrm{d}}$ \\
\hline WG film containing $20 \mathrm{mg}$ NA per $10 \mathrm{~g}$ film solution (T9) & $3.97 \pm 0.75^{b}$ & $2.81 \pm 0.28^{c}$ & $1.87 \pm 0.5^{\mathrm{d}}$ & $<10^{\mathrm{d}}$ \\
\hline
\end{tabular}

${ }^{\mathrm{a}-\mathrm{d}}$ Same letters show that there is no statistical difference between treatments at $P>0.05$.

with control film (T4) after 30 days of storage at $10^{\circ} \mathrm{C}$. However, application of MC films at and above $5 \mathrm{mg}$ NA per $10 \mathrm{~g}$ film solution resulted in nearly 2-log $\mathrm{CFU} \mathrm{g}^{-1}$ reduction in $A$. niger on cheese when compared to control sample (T3). Although minimum inhibitory concentration of NA containing $\mathrm{MC}$ films was determined as $2 \mathrm{mg}$ NA per $10 \mathrm{~g}$ film solution in in vitro studies, this value increased to $5 \mathrm{mg}$ NA per $10 \mathrm{~g}$ film solution for the cheese application. It was reported that antimicrobial films or coatings are more effective in terms of inhibiting target microorganisms as applied to nutrient media than on real systems owing to complex structure of foods (Dawson et al., 2002). In addition, increasing NA levels higher than $5 \mathrm{mg} / 10 \mathrm{~g}$ film solution did not provide further decrease in spore counts.

For WG films, logarithmic increase from 4.06 to 7.35 $\mathrm{CFU} \mathrm{g}^{-1}$ was also observed in A. niger-inoculated cheese during 30 days of storage (Table 2). Growth of moulds was completely inhibited on cheese packaged with WG films containing at and above $2 \mathrm{mg}$ NA per $10 \mathrm{~g}$ film solution, whereas 4.11-log reductions in mould population was determined on cheese packaged with WG control films (T4) after 30 days of storage compared to T3 (Table 2). The lowest concentration in which WG films completely eliminated A. niger was $2 \mathrm{mg}$ NA per $10 \mathrm{~g}$ film solution on cheese which was the same as for in vitro studies. Duan et al. (2007) also indicated that growth of moulds was completely inhib- ited on Mozzarella cheese packaged with chitosanlysozyme composite films. The decrease in mould populations covered with WG control films (T4) in our study could be attributed to a decrease in oxygen permeation into the package. Although MC films are more permeable to oxygen than WG films (Miller \& Krochta, 1997), the same degree of decrease in $A$. niger count was not observed for MC control film-wrapped cheese samples (T4 in Table 1). WG films absorbed water from cheese samples and covered the surface of the product very well without any oxygen headspace; thereby, visible mould growth was not observed on cheeses packaged with WG films (Fig. 1). Absorbed water may act as a plasticiser in WG films and increases the free volume of the gluten network, and also oxygen permeability of the film. In addition, this may lead to release of NA from polymer to the surface of cheese samples and eliminates the fungal spores during storage. This phenomena created by the water uptake on WG films were also demonstrated in another study (PochatBohatier et al., 2006).

\section{Effect of methyl cellulose and wheat gluten films containing} natamycin on Penicillium roquefortii inoculated on cheese

The antifungal activities of MC and WG films containing NA were also assessed on fresh kashar cheese using $P$. roquefortii as the microbial contaminant. Table 3
Figure 1 Suppression of Aspergillus niger by WG film (a) Control cheese without any film (b) WG film containing $5 \mathrm{mg}$ NA per $10 \mathrm{~g}$ film solution after 30 -day storage at $10{ }^{\circ} \mathrm{C}$.
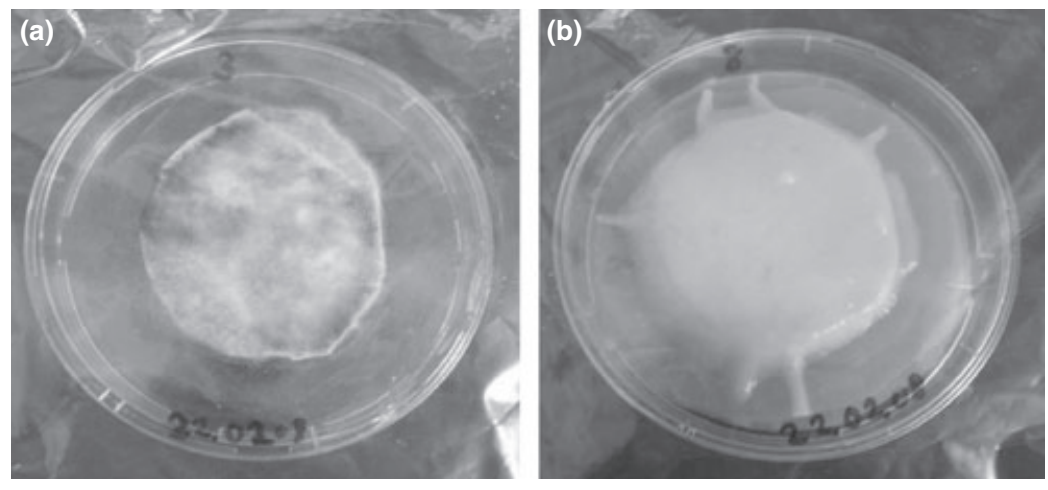
Biopolymers with natamycin on cheese $H$. Ture et al.

Table 3 Effect of MC films containing NA on the population $\left(\log \mathrm{CFU} \mathrm{g}^{-1}\right)$ of Penicillium roquefortii on kashar cheese during storage

\begin{tabular}{|c|c|c|c|c|}
\hline Treatments & Day 0 & Day 10 & Day 20 & Day 30 \\
\hline No treatment (T1) & $<10^{\mathrm{a}}$ & $<10^{\mathrm{a}}$ & $>10 x^{a}$ & \\
\hline UV-treated cheese (T2) & $<0^{\mathrm{a}}$ & $<0^{\mathrm{a}}$ & $>10 x^{a}$ & \\
\hline P. roquefortii-inoculated cheese (Т3) & $2.54 \pm 0.17^{b}$ & $7.22 \pm 1.38^{\mathrm{b}}$ & $7.25 \pm 1.9^{\mathrm{b}}$ & $7.74 \pm 0.64^{\mathrm{bc}}$ \\
\hline P. roquefortii-inoculated $+\mathrm{MC}$ control film (T4) & $2.6 \pm 0.33^{b}$ & $7.17 \pm 1.31^{\mathrm{bc}}$ & $7.23 \pm 1.61^{\mathrm{b}}$ & $7.84 \pm 0.83^{b}$ \\
\hline No treatment+MC control film (T5) & $<10^{\mathrm{a}}$ & $<10^{\mathrm{a}}$ & $>10 x^{a}$ & \\
\hline MC film containing $1 \mathrm{mg}$ NA per $10 \mathrm{~g}$ film solution (T6) & $2.54 \pm 0.18^{b}$ & $6.76 \pm 1.35^{\mathrm{d}}$ & $6.57 \pm 1.06^{\mathrm{c}}$ & $7.27 \pm 0.88^{d}$ \\
\hline MC film containing $2 \mathrm{mg}$ NA per $10 \mathrm{~g}$ film solution (T7) & $2.48 \pm 0.09^{\mathrm{b}}$ & $6.77 \pm 1.41^{d}$ & $6.60 \pm 1.33^{\mathrm{c}}$ & $7.41 \pm 1.13^{\mathrm{d}}$ \\
\hline MC film containing $5 \mathrm{mg}$ NA per $10 \mathrm{~g}$ film solution (T8) & $2.68 \pm 0.49^{\mathrm{b}}$ & $6.86 \pm 1.25^{\mathrm{d}}$ & $6.47 \pm 1.66^{\mathrm{c}}$ & $7.49 \pm 0.98^{\mathrm{cd}}$ \\
\hline MC film containing $10 \mathrm{mg}$ NA per $10 \mathrm{~g}$ film solution (T9) & $2.65 \pm 0.05^{\mathrm{b}}$ & $6.87 \pm 1.06^{\mathrm{d}}$ & $6.40 \pm 1.67^{\mathrm{c}}$ & $7.25 \pm 0.74^{\mathrm{d}}$ \\
\hline MC film containing $20 \mathrm{mg}$ NA per $10 \mathrm{~g}$ film solution (T10) & $2.60 \pm 0.27^{b}$ & $6.90 \pm 0.75^{\mathrm{cd}}$ & $6.57 \pm 0.24^{\mathrm{c}}$ & $7.40 \pm 0.24^{\mathrm{cd}}$ \\
\hline
\end{tabular}

${ }^{\mathrm{a}-\mathrm{d}}$ Same letters show that there is no statistical difference between treatments at $P>0.05$.

shows the antimicrobial effect of MC films containing NA at various concentrations against $P$. roquefortii. Population of $P$. roquefortii inoculated on control cheese samples increased from 2.54 to $7.74 \mathrm{CFU} \mathrm{g}^{-1}$ after 30 days of storage. MC control film and MC films containing various levels of NA did not cause any significant decrease in $P$. roquefortii population on cheese samples during 30 days of storage at $30{ }^{\circ} \mathrm{C}$. MC films containing $1 \mathrm{mg}$ NA per $10 \mathrm{~g}$ film solution were inhibitory against $P$. roquefortii in in vitro tests (Ture et al., 2008). According to our observations from previous in vitro work and this study on real food sample, P. roquefortii grew slowly on PDA at $30^{\circ} \mathrm{C}$; however, the same mould grew fast and completely covered the cheese slice at $10{ }^{\circ} \mathrm{C}$ after 20 days of storage. This result indicated that kashar cheese and refrigeration temperature are a suitable environment for $P$. roquefortii, and resistance of this mould to NA was more in this ideal growth environment compared to in vitro conditions.

As for WG films, a logarithmic increase from 2.40 to $7.78 \mathrm{CFU} \mathrm{g}^{-1}$ was also observed in P. roquefortii inoculated on fresh kashar cheese after 30 days of storage (Table 4). As it can be seen from Table 4, WG films containing 1 and $2 \mathrm{mg}$ NA (T6 and T7) did not cause significant inhibitory effect compared to control sample groups of T3 and T4. While even control WG films were inhibitory against $A$. niger, control and low concentration NA containing WG films (T6 and T7) were not effective against $P$. roquefortii. This difference again could be attributed to the better resistance of $P$. roquefortii against NA on a nutritious environment for growth. There was a slight decrease in spore count (approximately $0.75-0.95 \mathrm{log}$ ) at and above $5 \mathrm{mg}$ NA level (T8-T10) with respect to T3 control group at the end of 30 days of storage period.

In earlier studies, antimycotic activity of NA incorporated films has been shown against several moulds. Var et al. (2006) reported that packaging materials (PVC, Sperdex-Ref. 99017) in combination with NA applied to the surface of kashar cheese prevented mould formation during 2 months of ripening period. In the study of Cong et al. (2007), the bilayer coating of chitosan and polyethylene wax microemulsion including NA demonstrated inhibitory effect against two pathogenic fungi, Alternaria alternate and Fusarium semitectum, during 20-day storage of Hami melon at ambient temperature. Reps et al. (2002) used Delvocid containing $50 \%$ NA to protect the surface of several types of cheeses such as Gouda and Edam from mould growth.

Table 4 Effect of WG films containing NA on the population $\left(\log \mathrm{CFU} \mathrm{g}^{-1}\right)$ of Penicillium roquefortii on kashar cheese during storage

\begin{tabular}{|c|c|c|c|c|}
\hline Treatments & Day 0 & Day 10 & Day 20 & Day 30 \\
\hline No treatment (T1) & $<10^{\mathrm{a}}$ & $<10^{\mathrm{a}}$ & $>10 x^{a}$ & \\
\hline UV-treated cheese (T2) & $<10^{a}$ & $<10^{\mathrm{a}}$ & $>10 x^{a}$ & \\
\hline P. roquefortii-inoculated cheese (T3) & $2.40 \pm 0.01^{\mathrm{b}}$ & $7.14 \pm 1.84^{b}$ & $7.55 \pm 1.67^{b}$ & $7.78 \pm 0.73^{b}$ \\
\hline P. roquefortii-inoculated + WG control film (T4) & $2.30 \pm 0.01^{\mathrm{b}}$ & $7.15 \pm 1.73^{b}$ & $7.52 \pm 1.95^{\mathrm{b}}$ & $7.61 \pm 1.66^{b}$ \\
\hline No treatment + WG control film (T5) & $<10^{\mathrm{a}}$ & $<10^{\mathrm{a}}$ & $>10 x^{a}$ & \\
\hline WG film containing $1 \mathrm{mg}$ NA per $10 \mathrm{~g}$ film solution (T6) & $2.94 \pm 0.31^{\mathrm{b}}$ & $5.47 \pm 1.95^{\mathrm{c}}$ & $7.06 \pm 1.8^{\mathrm{cd}}$ & $7.50 \pm 1.76^{b}$ \\
\hline WG film containing $2 \mathrm{mg}$ NA per $10 \mathrm{~g}$ film solution (T7) & $2.76 \pm 0.65^{b}$ & $5.44 \pm 0.63^{c}$ & $7.25 \pm 1.79^{\mathrm{bc}}$ & $7.24 \pm 1.7^{\mathrm{c}}$ \\
\hline WG film containing $5 \mathrm{mg}$ NA per $10 \mathrm{~g}$ film solution (T8) & $2.54 \pm 0.28^{b}$ & $5.11 \pm 1.73^{\mathrm{cd}}$ & $6.89 \pm 1.43^{\mathrm{cd}}$ & $6.99 \pm 1.33^{\mathrm{cd}}$ \\
\hline WG film containing $10 \mathrm{mg}$ NA per $10 \mathrm{~g}$ film solution (T9) & $2.40 \pm 0.01^{\mathrm{b}}$ & $5.05 \pm 1.88^{d}$ & $6.91 \pm 2.6^{\mathrm{cd}}$ & $6.83 \pm 1.06^{d}$ \\
\hline WG film containing $20 \mathrm{mg}$ NA per $10 \mathrm{~g}$ film solution (T10) & $2.51 \pm 0.18^{b}$ & $5.13 \pm 0.79^{\mathrm{cd}}$ & $6.66 \pm 1.44^{d}$ & $7.05 \pm 1.13^{\mathrm{cd}}$ \\
\hline
\end{tabular}

${ }^{\mathrm{a}-\mathrm{d}}$ Same letters show that there is no statistical difference between treatments at $P>0.05$. 
It was also reported that polyvinyl acetate including $0.05 \%$ NA effectively prevented the growth of undesirable moulds on the surface of cheeses (Reps et al., 2002).

Results of this study indicated that MC- and WGbased films incorporated with NA demonstrated antifungal function against $A$. niger inoculated on the surface of fresh kashar cheese during 30 days of storage at $10{ }^{\circ} \mathrm{C}$. MC films containing at and above $5 \mathrm{mg}$ NA per $10 \mathrm{~g}$ film solution stopped mould growth with respect to initial mould count and resulted in 2-log reductions when compared with control sample. On the other hand, WG films completely inhibited mould development at and above $2 \mathrm{mg}$ NA per $10 \mathrm{~g}$ film solution during storage. However, the same films were not very effective in inhibiting the growth of $P$. roquefortii. Therefore, especially WG film containing NA could have potential to be used in the prevention and control of toxigenic moulds on dairy products such as cheese samples as active packaging materials in combination with other preventive measures in a hurdle concept. Results of this study also confirm that it is important to test the films, in which they were found to have antimicrobial activity in vitro conditions, on real foods to verify their antimicrobial properties.

\section{Acknowledgments}

This study was financially supported by The Scientific and Technological Research Council of Turkey (TUBITAK-TOVAG Project No: 104O543).

\section{References}

Cagri, A., Ustunol, Z. \& Ryser, E.T. (2001). Antimicrobial, mechanical and moisture barrier properties of low $\mathrm{pH}$ whey protein-based edible films containing p-aminobenzoic or sorbic acids. Journal of Food Science, 66, 865-870.

Cagri, A., Ustunol, Z. \& Ryser, E.T. (2002). Inhibition of three pathogens on bologna and summer sausage using antimicrobial edible films. Journal of Food Science, 67, 2317-2324.

Chinnan, M.S. \& Cha, D.S. (2004). Biopolymer based antimicrobial packaging: a review. Food Science and Nutrition, 44, 223-237.

Cong, F., Zhang, Y. \& Dong, W. (2007). Use of surface coatings with natamycin to improve the storability of Hami melon at ambient temperature. Postharvest Biology and Technology, 46, 71-75.

Dawson, P.L., Carl, G.D., Acton, J.C. \& Han, I.Y. (2002). Effect of lauric acid and nisin impregnated soy based films on the growth of Listeria monocytogenes on turkey bologna. Poultry Science, 81, 721726.

Debeaufort, F. \& Voilley, A. (1997). Methylcellulose based edible films and coatings:2 mechanical and thermal properties as a function of plasticizer content. Journal of Agricultural and Food Chemistry, 45, 685-689.

Domenek, A., Brendel, L., Morel, M.H. \& Guilbert, S. (2004). Swelling behavior and structural characteristics of wheat gluten polypeptides films. Biomacromolecules, 5, 1002-1008.

Duan, J., Park, S.I., Daeschel, M.A. \& Zhao, Y. (2007). Antimicrobial chitosan-lysozyme films and coatings for enhancing microbial safety of mozzarella cheese. Journal of Food Science, 72, 359-362.

Eswaranandam, S., Hettiarachchy, N.S. \& Johnson, M.G. (2004). Antimicrobial activity of citric, lactic, malic, or tartaric acids and nisin-incorporated soy protein film against Listeria monocytogenes, Escherichia coli O157:H7, Salmonella gaminara. Journal of Food Science, 69, 79-84.

Fajardo, P., Martins, J.T., Fucinos, C., Pastrana, L., Teixeira, J.A. \& Vicente, A.A. (2010). Evaluation of chitosan-based edible film as carrier of natamycin to improve the storability of Saloio cheese. Journal of Food Engineering, 101, 349-356.

Gennadios, A., Hanna, M.A. \& Kurth, L.B. (1997). Application of edible coatings on meats, poultry and seafoods: a review. $L W T$-Food Science and Technology, 30, 337-350.

Guilbert, S., Gontard, N., Morel, M.H., Chalier, P., Micard, V. \& Redl, A. (2002). Formation and properties of wheat gluten films and coatings. In: Protein-Based Films and Coatings (edited by A. Gennadios). Pp.. 69-122. Boca Raton, FL, USA: CRC Press.

Lens, J.P., Graaf, L.A., Stevels, W.M. et al. (2003). Influence of processing and storage conditions on the mechanical and barrier properties of films cast from aqueous wheat gluten dispersions. Industrial Crops and Products, 17, 119-130.

Matche, R.S., Kulkarni, G. \& Raj, B. (2006). Modified ethylene acrylic acid film for antimicrobial activity. Journal of Applied Polymers Science, 100, 3063-3068.

Micard, V., Belamri, R., Morel, M.H. \& Guilbert, S. (2000). Properties of chemically and physically treated wheat gluten films. Journal of Agricultural and Food Chemistry, 48, 2948-2953.

Miller, K.S. \& Krochta, J.M. (1997). Oxygen and aroma barrier properties of edible films: a review. Trends in Food Science and Technology, 8, 228-237.

Min, L.J., Harris, J. \& Krochta, M. (2005). Antimicrobial effects of lactoferrin, lysozyme, and the lactoperoxidase system and edible whey protein films incorporating the lactoperoxidase system against Salmonella enterica and Escherichia coli O157:H7. Journal of Food Science, 70, M332-M338.

de Oliveira, T.M., Soares, N.F.F., Pereira, R.M. \& Fraga, K.F. (2007). Development and evaluation of antimicrobial natamycin-incorporated film in gorgonzola cheese preservation. Food Packaging and Technology, 20, 147-153.

Padgett, T., Han, I.Y. \& Dawson, P.L. (2000). Effect of lauric acid addition on the antimicrobial efficacy and water permeability of corn zein films containing nisin. Journal of Food Processing and Preservation, 24, 423-432.

Peressini, D., Breavin, B., Lapasin, R., Rizzotti, C. \& Sensidoni, A. (2003). Starch-methylcellulose based edible films: rheological properties of film-forming dispersions. Journal of Food Engineering, 59, $25-32$.

Pochat-Bohatier, C., Sanchez, J. \& Gontard, N. (2006). Influence of relative humidity on carbon dioxide sorption in wheat gluten films. Journal of Food Engineering, 77, 983-991.

Quintavalla, S. \& Vicini, L. (2002). Antimicrobial food packaging in meat industry. Meat Science, 62, 373-380.

Reps, A., Drychowski, L., Tomasik, J. \& Niewska, K. (2002). Natamycin in ripening cheeses. Pakistan Journal of Nutrition, 1, 243-247.

Roy, S., Weller, C.L., Gennadios, A., Zeece, M.G. \& Testin, R.F. (1999). Physical and molecular properties of wheat gluten films cast from heated film-forming solutions. Journal of Food Science, 64, 5760.

Ruckenstein, E. \& Park, J.S. (2001). Viscoelastic properties of plasticized methylcellulose and chemically crosslinked methylcellulose. Carbohydrate Polymers, 49, 373-381.

Santos, A.C.P., Soares, N.F.F., de Andrade, N.J., Silva, L.H.M., Camilloto, G.P. \& Bernardes, P.C. (2008). Development and evaluation of active packaging for sliced mozzarella preservation. Packaging Technology and Science, 21, 375-383.

Scannell, A.G.M., Hill, C., Ross, R.P., Marx, S., Hartmeier, W. \& Arendt, K.E. (2000). Development of bioactive food packaging materials using immobilized bacteriocins lacticin 3147 and nisaplin. International Journal of Food Microbiology, 60, 241249. 
Sebastien, F., Stephane, G., Copinet, A. \& Coma, V. (2006). Novel biodegradable films made from chitosan and poly(lactic acid) with antifungal properties against mycotoxinogen strains. Carbohydrate Polymers, 43, 185-193.

Sebti, I., Martial-Gros, A., Carnet-Pantiez, A., Grelier, S. \& Coma, V. (2005). Chitosan polymer as bioactive coating and film against Aspergillus niger contamination. Journal of Food Science, 70, 100-104.

Stark, J. (2003). Natamycin: an Effective Fungicide for Food and Beverages. In: Natural Antimicrobials for the Minimal Processing of Foods (edited by S. Roller). Pp. 82-97. Cambridge, GBR: Woodhead Publishing.

Ture, H., Eroglu, E., Soyer, F. \& Ozen, B. (2008). Antifungal activity of biopolymers containing natamycin and rosemary extract against Aspergillus niger and Penicillium roquefortii. International Journal of Food Science and Technology, 43, 2026-2032.
Turhan, K.N. \& Şahbaz, F. (2004). Water vapor permeability, tensile properties and solubility of methylcellulose-based edible films. Journal of Food Engineering, 61, 459-466.

Var, I., Erginkaya, Z., Güven, M. \& Kabak, B. (2006). Effects of antifungal agent and packaging material on microflora of kashar cheese during storage period. Food Control, 17, 132-136.

Weng, Y.M. \& Chen, M.J. (1997). Sorbic anhydride as antimycotic additive in polyethylene food packaging films. LWT-Food Science and Technology, 30, 485-487.

Yildirim, M., Gulec, F., Bayram, M. \& Yildirim, Z. (2006). Properties of kashar cheese coated with casein as a carrier of natamycin. Italian Journal of Food Science, 18, 127-138.

Zivanovic, S., Chi, S. \& Draughon, A.N. (2005). Antimicrobial activity of chitosan films enriched with essential oils. Journal of Food Science, 70, 45-51. 